\title{
Determinants of primary care physicians' practice of prostate cancer counseling and screening
}

\author{
Danny M. Rabah, Mostafa A. Arafa*
}

King Saud University, Princess Al Johara Al Ibrahim Center for Cancer research, Riyadh, Saudi Arabia; *Corresponding Author: mostafaarafa@hotmail.com.

Received 5 August 2010; revised 12 August 2010; accepted 31 August 2010.

\begin{abstract}
Objective: The objective was to examine practices of primary care physicians and its determinants towards prostate cancer screening. Methods: Data was obtained from 204 primary care physicians using self-reports of prostate cancer screening practices, knowledge, attitudes towards prostate cancer screening. Results: nearly half of the respondent $(54.7 \%)$ were practicing counseling and referring prostate cancer patients. The mean correct knowledge score was $54.3 \%$, their attitude was not strong; the only statement that nearly seventy percent of physicians agreed upon was about the value of screening, however, the reliability and evidence to support DRE \& PSA were in question. Knowledge and attitude were found to be the most significant predictors that determine physicians' self practice. Conclusion: Background information and attitudes are important determinants of physicians' practice behavior towards prostate cancer counseling and referral in our study.
\end{abstract}

Keywords: Cancer Prostate; Counseling; Screening

\section{INTRODUCTION}

Prostate cancer (PC) is the second leading cause of cancer death nationwide for men over age 60 years. Currently, there is no scientific consensus on effective strategies to reduce the risk of PC [1]. Additionally, there is no agreement on the effectiveness of screening or that the potential benefits outweigh the risks [2]. Public health agencies are recommending that physicians and patients should reach a decision about screening collaboratively via shared decision making [2-5]. This allows patients to be informed about the benefits and risks of PC screening, treatment and to include their own values and preferences in the process.
Primary care physicians play an important role in cancer care and screening but relatively little is known about their PC knowledge, practice and training [6]. Physician surveys revealed that different doctors have different beliefs and practices about PC screening and counseling [7-9]. Chan and colleagues found that physicians do not agree on the facts that men need to know and to make an informed decision about PC screening [8]. In Saudi Arabia, physicians' practice and its determinants towards PC screening have never been examined. Understanding these perceptions will help identify continuous medical education (CME) training needs of physicians. This will guide tailoring an effective CME program about $\mathrm{PC}$ counseling and decision making that could be integrated into primary care prevention. Therefore, this study aimed to assess primary care physicians' practice skills and their attitude towards prostate cancer counseling, screening and referral.

\section{SUBJECTS AND METHODS}

\subsection{Study Design and Setting}

A cross-sectional descriptive study was conducted in the city of Riyadh (the capital of Saudi Arabia) during the period May through October 2009. All Primary health care physicians were invited to participate in the study. The survey questionnaire was sent to Physicians in different institutions. University hospitals, Army hospitals, Ministry of health hospitals and King Faisal specialized hospital representing different health sectors in the city. The study was approved by the research ethics committee at the authors' hospital and at each of the participants' hospitals.

\subsection{Study Tools}

A self-administered structured questionnaire was developed. It included the following information: Personal data, characteristics of prostate cancer counseling and screening (PCC\&S). Eight questions were used to assess 
time devoted in PCC\&S, percentage of patients suspected and referral for PSA reasons for PCC\&S with asymptomatic patients, issues discussed during PC counseling, rating their skills in PCC\&S, resourced used to get information about PC. Physicians' knowledge about PC: This scale comprised 29 questions that examined knowledge regarding different facts about the prostate. For each question the correct answer was given a score of one and incorrect answer was given zero. Physicians' attitudes towards PCC\&S: A scale of nine items was designed as three points Likert scale (agree, neutral, disagree) to ascertain physicians' attitude toward accuracy and evidence supporting screening as well as their role in screening. For each item, the response was scored from 1-3 with higher score for more favorable attitude toward PCC\&S.

\subsection{Statistical Analysis}

Data was processed and analyzed by SPSS, version 17. AVOVA test and t test were used as tests of significance. The level of significance used was at $p$ value $<0.05$. For testing internal consistency of different scales, Chronbach $\alpha$ reliability test was used, 0.65 for attitude scale and 0.75 for knowledge scale. Logistic regression was used to explore the effect of different factors predicting the physicians' practice towards prostate cancer counseling and screening, the dependent variable was physicians' referral versus non referral.

\section{RESULTS}

Out of the 405 primary health care physicians surveyed, 204 returned the questionnaire, giving a response rate $50.3 \%$. Fifty six questionnaires were excluded due to incomplete answers, giving a final total of 148 responses. The mean age of the participants was $41.35 \pm 8.83$ years (range, 25-60 years). Only 21(14.2\%) were non Arabic speakers. The mean years of experiences were $3.61 \pm 1.37$ years.

The present study revealed that nearly half of the respondents $(54.7 \%)$ were counseling, screening and sometimes referring PC patients, the main reasons were the age of the patient; being above $50(35.8 \%)$, family history $(31.8 \%)$ and upon patient's request $(23.3 \%)$.

In general, in terms of percentage, the mean correct knowledge score was $54.3 \%$ (Table 1). Regarding different knowledge items, the majority of the respondents knew that age above 50 years, family history, black race, and tobacco smoking are risk factors of PC. The least known risk factors were high fat diet and obesity $(50 \%)$ and multiple sex partners $(20.9 \%)$. The most frequent medical problems that make PHC physicians recommend PC screening were weak urinary stream $(81.1 \%)$,
Table 1. Distribution of the PHC physicians by their correct knowledge about PC and screening.

\begin{tabular}{|c|c|c|}
\hline Knowledge items & No (148) & $\%$ \\
\hline \multicolumn{3}{|l|}{ Risk factors: } \\
\hline -Age below 50 year $(\mathrm{F})$ & 128 & 86.5 \\
\hline -Family history & 121 & 81.8 \\
\hline -White race $(\mathrm{F})$ & 111 & 75.0 \\
\hline -Tobacco smoking & 107 & 72.3 \\
\hline -High fatty diet and obesity & 74 & 50.0 \\
\hline -Number of man's sexual partners & 31 & 20.9 \\
\hline \multicolumn{3}{|l|}{ Medical problems to recommend PC screening : } \\
\hline -Weak urinary stream & 120 & 81.1 \\
\hline -Hematuria & 106 & 71.6 \\
\hline -Blood in semen & 98 & 66.2 \\
\hline -Family history & 97 & 65.5 \\
\hline -Starting \& stopping while urinating & 89 & 60.1 \\
\hline -Frequent pain or stiffness in the lower back & 88 & 59.5 \\
\hline -Increased urinary urgency & 86 & 58.1 \\
\hline -Increased urinary frequency & 75 & 50.7 \\
\hline -Nocturia & 61 & 41.2 \\
\hline -Painful ejaculation & 59 & 39.9 \\
\hline -Erectile dysfunction & 46 & 31.1 \\
\hline Function of the prostate & 88 & 59.5 \\
\hline Normal value of PSA for a man under 60 year & 102 & 68.9 \\
\hline \multicolumn{3}{|l|}{ PC routine screening: } \\
\hline -PSA & 117 & 79.1 \\
\hline -DRE & 103 & 69.6 \\
\hline -Transrectal ultrasound & 44 & 29.7 \\
\hline Can false positive PSA test occur & 129 & 87.2 \\
\hline $\begin{array}{l}\text { Nutrients recommended for prevention of PC; } \\
\text {-Selenium }\end{array}$ & 23 & 15.5 \\
\hline -Vitamin E & 48 & 32.4 \\
\hline -Green Tea & 34 & 22.9 \\
\hline -Low fat diet & 88 & 59.5 \\
\hline -vitamin D & 8 & 5.4 \\
\hline \multirow{2}{*}{$\begin{array}{l}\text { - vitamin D } \\
\text {-Beta carotenes }\end{array}$} & 17 & 11.5 \\
\hline & 33 & 22.3 \\
\hline
\end{tabular}

and hematuria $(71.6 \%)$, meanwhile the least mentioned were painful ejaculation $(39.9 \%)$ and erectile dysfunction $(31.1 \%)$. Only $59.5 \%$ and $68.9 \%$ knew correctly the function of prostate and normal value of PSA for a man under 60 year respectively. Also, 79.1\% and 68.9\% knew that PSA and DRE are used for routine PC screening. Uncertainty about nutritional knowledge was evident among PHC physicians.

As shown in Table 2, the mean total attitude score was 19.25 which was slightly higher than midpoint (18) of the actual range of that score (9-27). For different attitudinal statements, "It is more appropriate for specialists to screen for PC" had got the highest favorable mean score (2.64) which delineates that the majority of PHC physician accepting PCC\&S to be their role. Also 
Table 2. PHC physicians' attitudes towards PCC\&S.

\begin{tabular}{|c|c|c|c|}
\hline Attitude statements & Agree \% & Mean (Range 1-3) & SD \\
\hline 1) Early detection through screening can improve survival for men with PC & 71.6 & 2.62 & .65 \\
\hline 2) PCC\&S should be routinely used on all men beginning at age 50 & 43.2 & 2.22 & .77 \\
\hline 3) DRE is an accurate screening test for prostate cancer & 16.2 & 1.85 & .67 \\
\hline $\begin{array}{l}\text { 4) There is evidence to support using DRE for PC screening on asymptomatic men with no risk } \\
\text { factors }\end{array}$ & 20.3 & 1.80 & .75 \\
\hline 5) DRE is unaccepted from Saudi men, so physicians should avoid it & 8.1 & 2.51 & .64 \\
\hline 6) PSA is an accurate screening test for prostate cancer & 27.0 & 1.91 & .79 \\
\hline $\begin{array}{l}\text { 7) There is enough evidence to support using PSA for PC screening on asymptomatic men with } \\
\text { no risk factors }\end{array}$ & 17.6 & 1.66 & .76 \\
\hline 8) It is more appropriate for specialists to screen for PC & 10.8 & 2.64 & .67 \\
\hline 9) I think that PSA testing leads to excess subsequent unnecessary investigations & 29.7 & 2.04 & .79 \\
\hline Total attitude score (actual range 9-27) & & 19.25 & 2.97 \\
\hline
\end{tabular}

the majority had favorable attitudes towards "Early detection through screening can improve survival for men with PC" $(\overline{\mathrm{x}}=2.62)$. The least favorable attitude scores were for the reliability and accuracy of DRE and PSA testing.

The results of the final model of logistic regression is presented in Table 3, it appears that total knowledge score and total attitude score were the most significant variables that could predict physicians' practicing towards PCC \& S, while self efficacy had border line significance.

\section{DISCUSSION}

It was found that physicians who were influenced by scientific evidence were more likely to practice informed decision making with their patients particularly primary health care physicians who are more likely to believe that men need to know facts about uncertainties of PSA testing to make such decision [10].

Nearly half of the physicians $(54.7 \%)$ in the present study were practicing PCC \& S, their mean correct knowledge score was $54.3 \%$ and their attitude towards PCC \& S in the current study was not strong. An interesting finding which should be addressed: that despite the majority of respondents hold a strong belief that PCC $\& \mathrm{~S}$ is mainly their role, their practice towards in counseling, screening and/or referral was poor. The results of Curran et al. suggested that the vast majority of primary care physicians in Newfoundland and Labrador screen asymptomatic male patients for prostate cancer, and they had very positive attitudes towards prostate screening, where most of them agreed that prostate screening should be routinely performed on all men beginning at age 50 and that early detection with screening can im-
Table 3. Determinants of physicians' practice towards prostate cancer counseling and screening.

\begin{tabular}{cccccc}
\hline Variables & B & S.E. & $\begin{array}{c}\text { Odds } \\
\text { Ratio }\end{array}$ & \multicolumn{2}{c}{$\mathbf{9 5 . 0 \%}$ C.I. } \\
\cline { 5 - 6 } & & & Lower & Upper \\
\hline $\begin{array}{c}\text { Total knowledge } \\
\text { score }\end{array}$ & -0.138 & .048 & .87 & 0.79 & 0.95 \\
$\begin{array}{c}\text { Total attitude } \\
\text { score }\end{array}$ & -0.183 & .071 & .83 & 0.72 & 0.95 \\
$\begin{array}{c}\text { Total self-efficacy } \\
\quad \text { score }\end{array}$ & -0.011 & .009 & .98 & 0.97 & 1.002 \\
$\begin{array}{c}\text { Years of } \\
\text { experience }\end{array}$ & 0.07 & .144 & .93 & 0.70 & 1.25 \\
$\begin{array}{c}\text { Previous CME in } \\
\text { PC }\end{array}$ & 0.69 & .67 & 1.99 & 0.53 & 7.45 \\
\hline
\end{tabular}

prove survival for men with prostate cancer [11]. On the other hand, Pendelton J. and his colleagues found that the mean correct score on the knowledge questions was $59 \%$, only $52 \%$ of physicians in that study reported routine screening in minority men and that physicians' knowledge is not an important predictor of their screening behavior [12].

Our results implied that knowledge and attitude were the most important significant predictors of physicians' practice of PCC \& S, which came in accordance with previous researchers revealed that physician knowledge of specific disease process greatly influenced screening behavior [3-15] and a positive attitude towards screening can be a significant predictor of ordering or performing such screening tests $[13,16,17]$.

The results of the present study support the fact that physicians' practice towards a screening procedures or early detection of diseases should rely on a good background of information which in turn enhances their self efficacy and develops a good and positive attitude towards their practice skills. Further research should be 
undertaken to recognize how to assist men make informed decisions about prostate cancer testing.

\section{REFERENCES}

[1] Greenwald, P., Dunn, B.K. (2009) Do we make optimal use of the potential of cancer prevention? Recent Results in Cancer Research, 181, 3-17.

[2] CDC (2006) Prostate cancer: Informed decision making: How to make a personal health care choice. http://www.cdc.gov/cancer/prostate/informed_decision_ making.htm

[3] Orom, H., Penner, L.A., West, B.T., Downs, T.M., Rayford, W. and Underwood, W. (2009) Personality predicts prostate cancer treatment decision-making difficulty and satisfaction. Psychooncology, 18(3), 290-299.

[4] U.S. Preventive Services Task Force (2002) Screening for prostate cancer: Recommendation and rationale. $\mathrm{An}$ nals of Internal Medicine, 137, 915-916.

[5] Hoffman, R.M. and Helitzer, D.L. (2007) Moving towards shared decision making in prostate cancer screening. Journal of General Internal Medicine, 22(7), 10561057.

[6] Wong, J.E. (2005) The role of the primary-care physician in oncology care. Primary care in Singapore. The Lancet Oncology, 6(2), 118-119.

[7] Purvis, C., Merritt, T.L., Ross, L.E., Johj, L.V. and Jorgensen, C.M. (2004) To screen or not to screen, when clinical guidelines disagree: Primary care physicians' use of the PSA test. Preventive Medicine, 38(2), 182-191.

[8] Chan, E.C., Vernon, S.W., Haynes, M.C., O’Donnell, F.T. and Ahn, C. (2003) Physician perspectives on the importance of facts men ought to know about prostate-specific antigen testing. Journal of General Internal Medicine, 18 (5), 350-356.

[9] Voss, J.D. and Schectman, J.M. (2001) Prostate cancer screening practices and beliefs: A longitudinal physician study. Journal of General Internal Medicine, 16(12), 831-
837.

[10] Purvis, C.C., Merritt, T.L., Ross, L.E., John, L.V. and Jorgensen, C.M. (2004) To screen or not to screen, when clinical guidelines disagree: Primary care physicians' use of the PSA test. Preventive Medicine, 38(2), 182-191.

[11] Curran, V., Solberg, S., Mathews, M., Church, J., Buehler, S., Wells, J. and Lopez, T. (2005) Prostate cancer screening attitudes and continuing education needs of primary care physicians. Journal of Cancer Education, 20(3), 162166

[12] Pendelton, J., Curry, R.W., Kaserian, A., Chang, M., Anai, S., Nakamura, K., Abdoush, P. and Rosser, C.J. (2008) Knowledge and attitudes of primary care physicians towards prostate cancer screening. Journal of the National Medical Association, 100(6), 666-670.

[13] Livingston, P., Cohen, P., Frydenberg, M., Borland, R., Reading, D., Clarke, V. and Hill, D. (2002) Knowledge, attitudes and experience associated with testing for prostate cancer: A comparison between male doctors and men in the community. Internal Medicine Journal, 32(5-6), 215-223.

[14] Philips, G.K., Reinier, K., Ashikaga, T., et al. (2005) Attitudes and beliefs of primary care physicians regarding prostate and colorectal cancer screening in a rural state. Journal of Cancer Education, 20, 167-172.

[15] Smith, R.A., Cokkinides, V. and Eyre, H.J. (2006) American Cancer Society guidelines for the early detection of cancer, CA: A Cancer Journal for Clinicians, 56, 11-25.

[16] Hoag, N.A., Davidson, R.A. and Pommerville, P.J. (2008) Prostate cancer screening practices and attitudes among primary care physicians in Victoria, British Columbia. $B C$ Medical Journal, 50(8), 456-460.

[17] Tudiver, F., Guibert, R., Haggerty, J., Ciampi, A., Medved, W., Brown, J.B., Herbert, C., Katz, A., Rivto, P., Grant, B., Goel, V., Smith, P., O’Beirne, M., Williams, J.L. and Moliner, P. (2002) What influences family physicians' cancer screening decisions when practice guidelines are unclear or conflicting? The Journal of Family Practice, 51(9), 760-766. 